\title{
The possibility of significantly increasing the degree of regeneration in regene rative gas turbine plants without increasing the size of the recuperator.
}

\author{
Sergei V. Sevtsov \\ Engineer-constructor. Independent researcher. Russia.
}

Contact: E-mail: $\underline{30071962 @ m a i l . r u ~}$

\begin{abstract}
The proposed article considers the theoretical prerequisites and proposes a scheme for a regenerative gas turbine installation with an increase in the degree of regeneration at constant recuperator sizes in order to increase the efficiency of the installation. The new scheme excludes the supply of secondary (cooling the heat pipe and combustion products in the combustion chamber) air to the heat exchanger for heating. Reducing the air flow in the recuperator to the values of only the primary (for fuel oxidation) air flow with the recuperator area unchanged leads to an increase in the degree of regeneration and, accordingly, the efficiency of the plant.
\end{abstract}

Running title: Sevtsov's scheme.

Keywords: air separation in gas turbine plants, excess air factor, gas- air heat exchanger, hydraulic heat exchanger resistance, efficiency coefficient.

\section{Introduction}

As is known in modern and prospective small size gas turbine plants (GTP) used a scheme with heat regeneration due to the difficulty of implementing a high compression degree with high efficiency coefficient. The principle is to use some of the heat available in the exhaust gases to heat the air coming out of the compressor before it enters the combustion chamber.

In contrast to the non-regeneration circuit, when the recuperator (non-rotating gas-air heat exchanger) is used, the air temperature at the inlet to the combustion chamber increases, so less fuel consumption is required to obtain the same gas temperature before the turbine. There is a great variety of actually tested structures of recuperators [1].

At the time of writing, the regenerative gas turbine unit with the largest efficiency coefficient $-41.5 \%$ is the Mercury 50 with an average capacity of 4.3 MW from firm "Solar" [2].

The installation is described in Fig.1 [3].

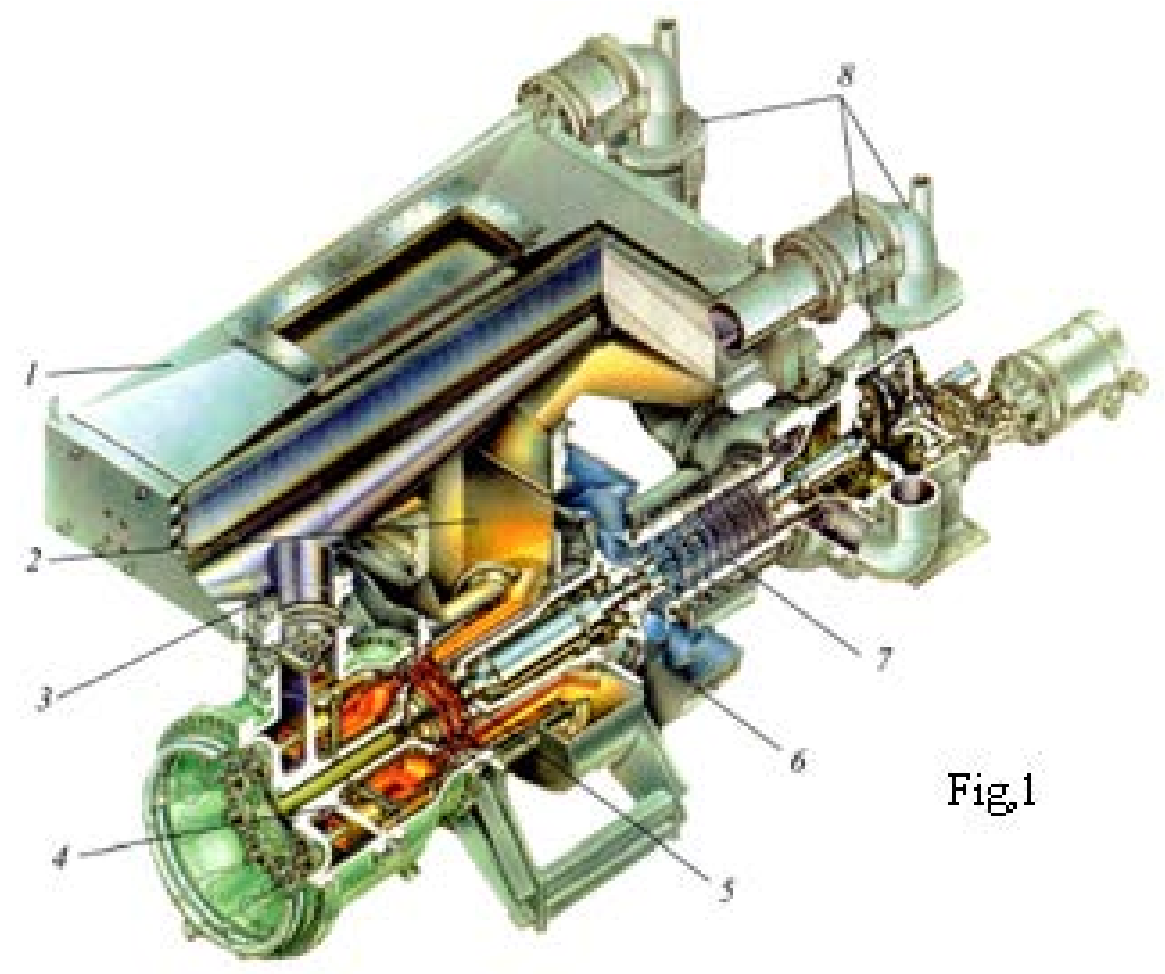


Fig. 1. Single-shaft GTP Mercury 50 from firm «Solar» with recuperator 4.6 MW capacity:

1 - recuperator;

2 - channel gas supply from the turbine to the recuperator;

3 - air supply channel from recuperator to combustion chamber;

4 - external combustion chamber;

5 - turbine;

6 - input device;

7 - compressor;

8 - air supply piping from compressor to recuperator.

In this GTP, in order to reduce gas-dynamic losses in the gas-air tract, as well as to reduce the weight and size indicators, an original layout was used (Fig. 2): the air inlet to the compressor and the combustion products outlet from the turbine are located in the central part, and the compressed air outlet to the regenerator and the combustion chamber are from opposite ends. The recuperator is placed between the air outlet from the compressor and its entry into the combustion chamber along the axis of the GTP [4].
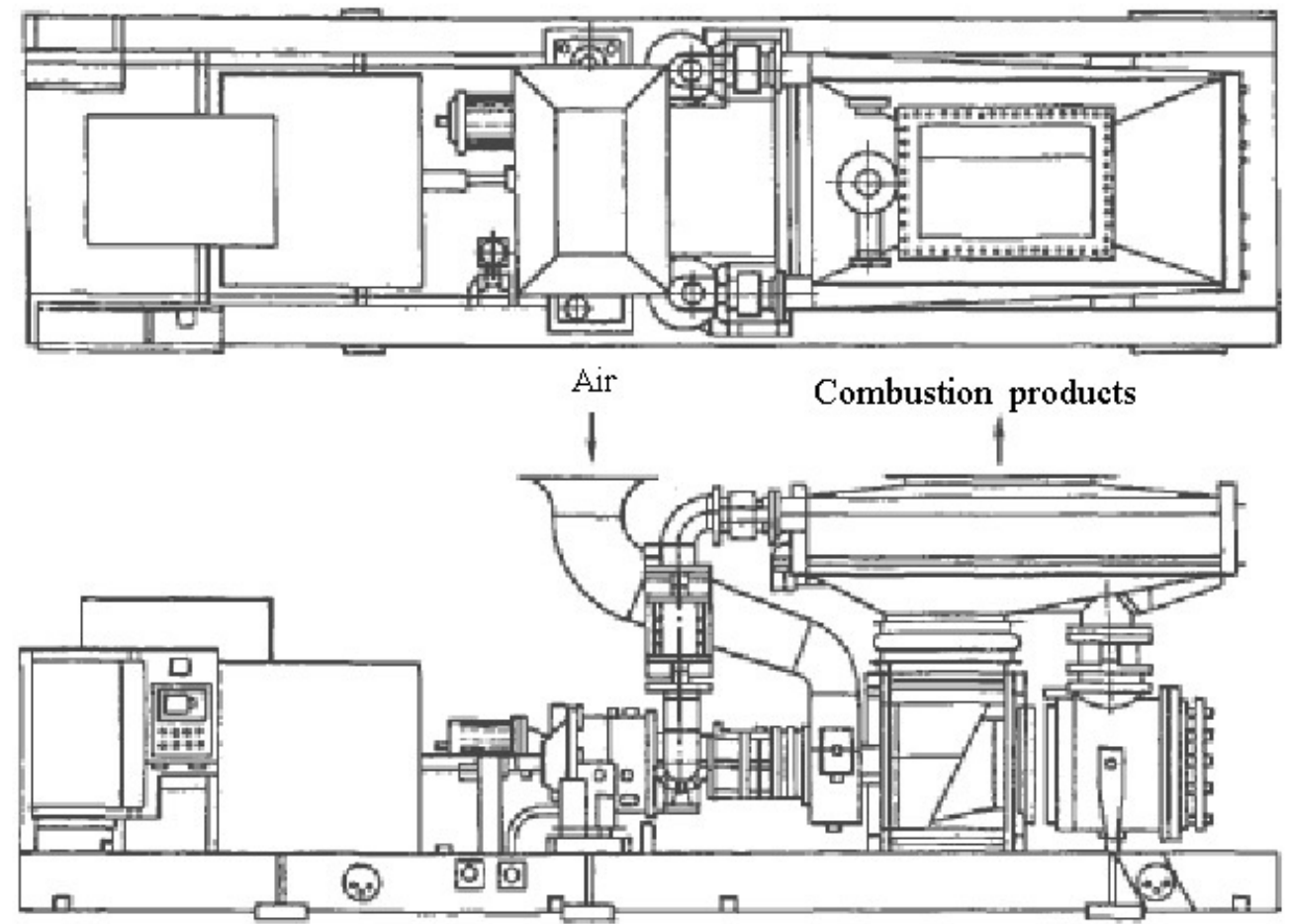

Fig. 2. Arrangement of the regenerative energy GTP "Mercury-50".

The installation was developed under the program -Advanced Turbine Systems of the US Department of Energy (1992-2000). The success was achieved by using a heat exchanger with a high (up to 90\%) degree of heat regeneration. Later (2001-2015), the US Department of Energy implemented a new program NGGT ("Next Generation Gas Turbines") [5].

But, alas, the achievement of the company «Solar» - efficiency coefficient $41.5 \%$ for small regenerative gas turbine units was not exceeded.

In fact, we have a technological deadlock - improving the characteristics of recuperators does not lead to an increase in the efficiency coefficient of these installations.

The article discusses the reasons that led to the emergence of the efficiency coefficient growth limit of modern regenerative gas turbine plants. The article also proposes a scheme for radically changing the designs of regenerative plants for the option of overcoming the emerging technological impasse.

\section{Theoretical Basis}

For the development and explanation of the ideas presented in the article, the scheme of the gas turbine 
installation by engineer Sukhachev, which was published by him in 1934, is important [6].

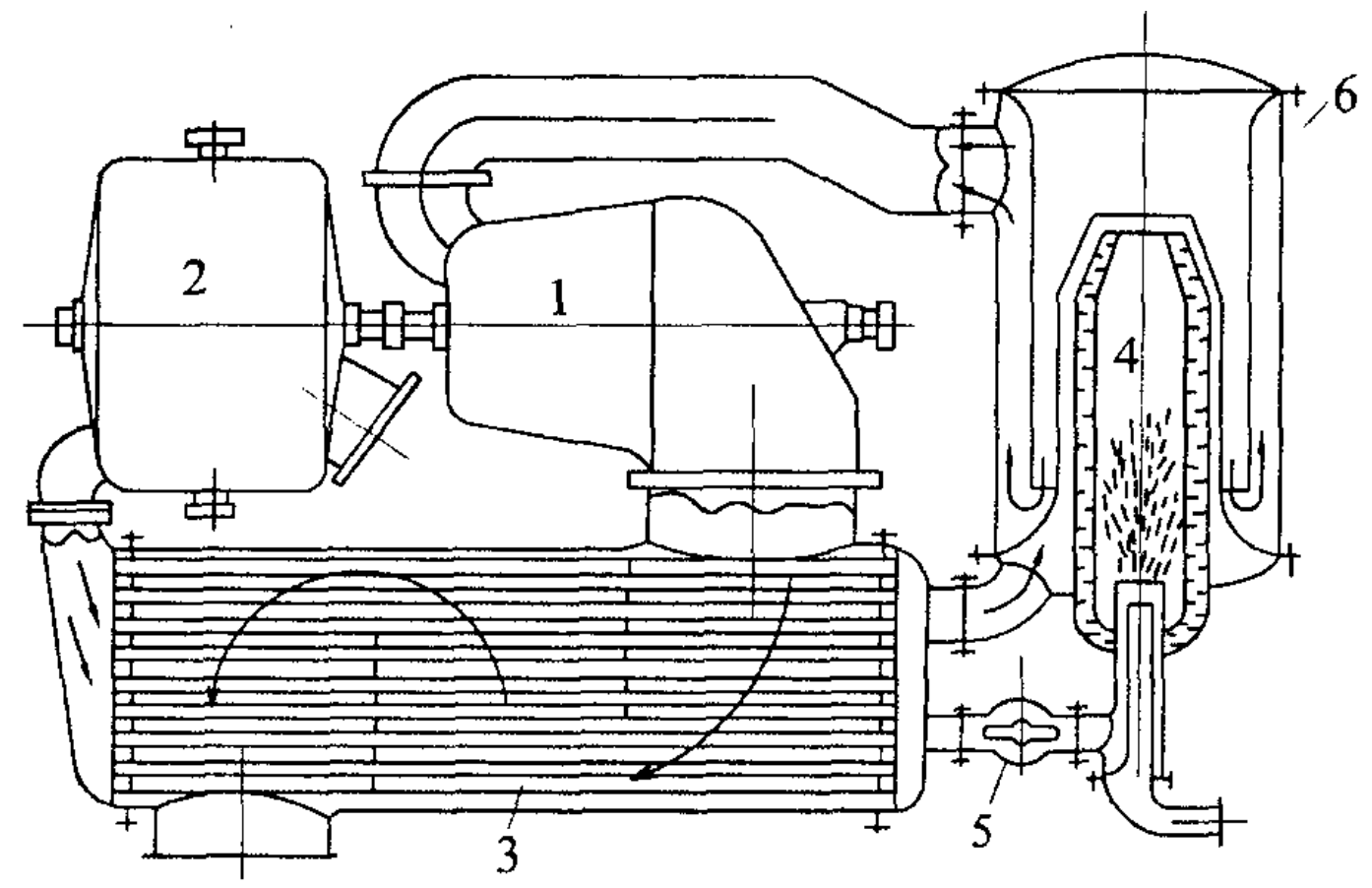

Fig. 3. Scheme of a gas turbine unit with a recuperator from Sukhachev:

1-gas turbine;

2-air compressor;

3-regenerator (recuperator);

4-combustion chamber;

5-primary air regulator;

6-cylinder for mixing gases and air.

Sukhachev's scheme in general terms coincides with modern schemes of gas turbine installations with recuperators.

In modern regenerative gas turbine installations, there is no primary air regulator - item 5 (combustion chambers with variable geometry are much more complicated). The cylinder of mixing gases and air item 6 is the body of the combustion chamber.

The combustion chamber in the Sukhachev's scheme fundamentally coincides with the design of the combustion chambers of modern gas turbine installations [7].

So the presence of large excess air in the chambers plays a very important role. When designing chambers, certain methods of dividing the total air flow into separate parts are provided. One part (primary air) ensures the flow of the combustion process and its individual stages at the most favorable ratios of the combustible mixture, while the high temperatures and intensive mixing necessary for rapid combustion of fuel are provided in the flame part of the chamber. The other part of the air is used to cool the elements of the chamber, which are strongly heated by a burning torch, and then mixed with combustion products to lower their temperature to the values necessary for the normal operation of the turbine. Thus, in the chambers of gas turbine installations, only part of the air is directly involved in the fuel combustion process, while the other part has a limited service role of a cooler.

Let's return to our consideration of Sukhachev's scheme.

In the Sukhachev's scheme, there is also a separation of air into two streams in the combustion chamber. Only this separation takes place in front of the combustion chamber - there are two channels for removing air from the regenerator into the combustion chamber. One is for the primary air of the combustion chamber- the air for the fuel combustion process. The second is for the secondary air of the combustion chamber - air not for burning fuel, but for cooling the combustion chamber's heat pipe and cooling the combustion products from the heat resistance condition of the gas turbine. In modern designs, 
of course, these two channels are combined into one. Further in the article, the need for a second channel for the removal of secondary air from the regenerator will be considered. To be more precise, is it necessary to supply part of the air to the regenerator at all, which will then be used as a secondary in the combustion chamber?

Of course, the question of the need to maintain a separate primary air supply channel will be raised. Mathematical analysis should probably begin with the well-known definition of the excess air coefficient $-\alpha$ [8]. In general, the excess air coefficient $\alpha$ is equal to the ratio of the air flow rate GB through the allocated volume (in particular the heat pipe) to the theoretically necessary for complete combustion of fuel:

$$
\alpha=G_{\mathrm{B}} /\left(L G_{\mathrm{T}}\right)(1)
$$

where $\mathrm{G}$ т is the fuel consumption; $\mathrm{L}$ is the stoichiometric coefficient; $\mathrm{L}=14.73 . .14 .95$ depending on the brand of kerosene.

In [9] it is indicated that GTP operate at large excess air coefficients of the order $\alpha=3 \div 5$ for schemes without regeneration and $\alpha=5 \div 8$ for schemes with regeneration. Large air surpluses in GTP are explained by moderate values of the limiting temperature of the gas behind the combustion chamber (significantly lower than, for example, in internal combustion engines or in boiler furnaces) with quite significant, especially in schemes with regeneration, values of the air temperature in front of the combustion chamber.

So according to [10], for the estimated calculations of the excess air coefficient in the temperature range of the air (secondary cooling) Тк $=400 . . .900 \mathrm{~K}$ and the combustion products in front of the turbine $\mathrm{T}_{\Gamma}=800 \ldots 2000 \mathrm{~K}$, you can use the interpolation formula-

$$
\alpha=\frac{3000-0,367 T_{\mathrm{\Gamma}}}{T_{\mathrm{r}}-T_{\mathrm{K}}}(2)
$$

For a simple scheme of a gas turbine installation, the temperature of the cooling secondary air is equal to the temperature of the air after the compressor - Тк. For the regenerative circuit, this will be the air temperature after the recuperator - Te.

It can be seen from formula (2) that an increase in the temperature of the cooling heat pipe and the combustion products of secondary air after the recuperator at a constant temperature of gases in front of the turbine leads to an increase in the excess air coefficient $\alpha$ in regenerative gas turbine installations compared to simple schemes.

Let us consider the formulas of the specific gas flow rate $\mathrm{d}$, the specific work of gas $\mathrm{H}$, the power of the gas turbine unit $\mathrm{N}$, the degree of regeneration $\sigma$, the area of the heat transfer surface of the recuperator $\mathrm{f}$ and their interpretation according to [11].

Specific gas consumption $(\mathrm{kg} / \mathrm{kJ})-$

$$
d=G / N
$$

where $\mathrm{G}$ is the gas flow rate, $\mathrm{kg} / \mathrm{s}$; $\mathrm{N}$ is the net power of the gas turbine unit, $\mathrm{kW}$.

Specific work of gas $(\mathrm{kJ} / \mathrm{kg})$ -

$H=H_{\mathrm{T}}-H_{\mathrm{K}}$

where NT is the specific work of the turbine, $\mathrm{kJ} / \mathrm{kg}$; Nк is the specific work of the compressor, $\mathrm{kJ} / \mathrm{kg}$

The specific work of gas $\mathrm{H}$ is related to the specific flow rate $\mathrm{d}$ by a simple ratio-

$$
H=d^{-1}
$$

Formulas (3) and (5) are used to determine the power $\mathrm{N}$ of a gas turbine installation, $\mathrm{kW}$ -

$$
N=G / d=G H(6)
$$


The efficiency of the recuperator, as a heat exchanger, is estimated by the degree of regeneration $\sigma$, determined by the ratio of the amount of heat transferred to the air to the maximum possible amount of heat-

$$
\sigma=\frac{q_{\mathrm{B}}}{q_{\max }}=\frac{c_{p_{\mathrm{B}}}}{c_{p_{\mathrm{r}}}} \cdot \frac{T_{e}-T_{b}}{T_{d}-T_{b}} \approx \frac{T_{e}-T_{b}}{T_{d}-T_{b}}
$$

where- Te is the air temperature after the regenerator. This temperature is included in formula (2) instead of the air temperature after the Tк compressor for simple GTP circuits;

Tb- air temperature after compressor;

Td is the exhaust gas temperature after the turbine.

The specific surface area of the heat transfer surface of the heat exchanger $f$, related to the gas flow rate G-

$$
\frac{f}{G}=\frac{c p_{\mathrm{B}}}{K} \cdot \frac{\sigma}{1-\sigma}
$$

where: $\mathrm{C}_{\mathrm{p}}$ - the heat capacity of the air;

$\mathrm{K}$ - the heat transfer coefficient in the heat exchanger.

Expressing in the formula (8) the flow rate $\mathrm{G}$ through the power $\mathrm{N}$ and the specific useful work $\mathrm{H}$, we obtain the value of the surface of the recuperator, related to the power, in the form-

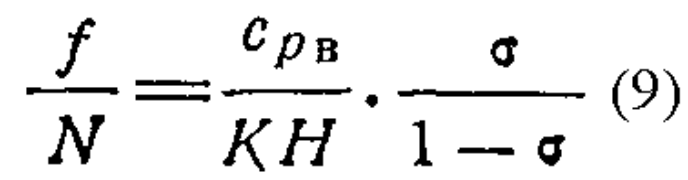

The obtained ratio shows that the specific surface of the recuperator $\mathrm{f} / \mathrm{N}$ depends on the degree of regeneration, and with $\sigma$ tending to unity, the ratio of $\mathrm{f} / \mathrm{N}$ increases indefinitely. This conclusion is easy to understand if we take into account that at $\sigma=1$ the temperature set between exhaust gases and air vanishes $(\mathrm{Te}=\mathrm{Td})$.

According to the author of the article, this is the technological impasse in the growth of efficiency coefficient of regenerative GTP - for the growth of efficiency coefficient, it is necessary to raise the degree of regeneration $\sigma$, that is, to raise the value of the specific surface of the recuperator - $f / G$ - the ratio of the area of the recuperator to the air flow through the recuperator. But at the same time, the area $f$ of the recuperator increases sharply and the resulting increase in the hydraulic resistance of the recuperator reduces all improvements to nothing. In other words, an increase in the degree of regeneration $\sigma$ due to an increase in the area of the recuperator $f$ to increase the specific surface of the recuperator - the ratio of the area of the recuperator to the air flow through the recuperator - $f / G$-no longer has technological (design) reserves. Another way is needed to increase the degree of regeneration $\sigma$ - not by increasing the area $f$ of the recuperator.

Let's return to the original source[11]. It also follows from formula (9) that a decrease in the specific surface of the recuperator can be achieved by intensifying heat transfer (increasing $\mathrm{K}$ ) and increasing the specific useful work of $\mathrm{N}$. An increase in $\mathrm{H}$ at a given power corresponds to a drop in the flow rate $\mathrm{G}$, and consequently, the amount of heat transferred in the heat exchanger from exhaust gases into the air.

It seems difficult to achieve the purpose of the article if we do not consider the arguments of Professor V.V. Uvarov about the specific power of Ny [12].

The undesirability of large coefficients of excess air $\alpha$ in modern GTP Uvarov V.V. explains on the known ratio-

$$
N_{\mathrm{y}}=\frac{N}{G}=\frac{H_{z} \eta_{e}}{\alpha L_{0}}(10)
$$


where - $\alpha$ is the coefficient of excess air;

$\mathrm{H}_{\mathrm{u}}$ - calorific value of fuel - $\mathrm{kJ} / \mathrm{kg}$;

$\mathrm{L}_{\mathrm{o}}$ - theoretically necessary amount of air for the combustion of one kilogram of air - kg;

$\mathrm{G}$ - air consumption - kg/sec;

$\mathrm{N}$ - installation power - $\mathrm{kW}$;

$\eta_{\mathrm{e}}$ - efficiency coefficient of the installation.

Uvarov V.V. calls the value of Nu specific power - the power of a gas turbine installation per $1 \mathrm{~kg}$ of air flowing through the installation in one second.

From the previously considered formula (6), the specific work of gas $\mathrm{H}$ is equal to -

\section{$H=N / G(11)$}

The analysis and comparison of the dimensions of the quantities in formulas (10) and (11) suggests that the specific power of $\mathrm{N}_{\mathrm{y}}$ according to Uvarov V.V. is the specific work of gas $\mathrm{H}$.

Thus, formula (10) will take the form-

$$
H=\frac{H_{u} \eta_{e}}{\alpha L_{0}}(12)
$$

Substitute in formula (9) the value of the specific work of the gas according to formula (12) -

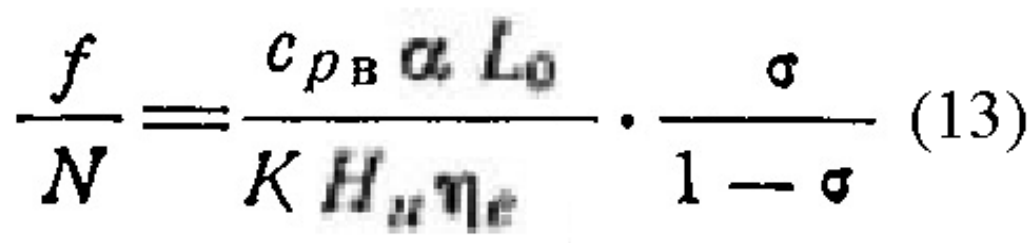

It follows from the newly obtained formula (13) that the specific surface of the recuperator $\mathrm{f} / \mathrm{N}$ depends on the excess air coefficient $\alpha$. With an increase in the value of excess air $\alpha$, the specific surface of the recuperator $\mathrm{f} / \mathrm{N}$ increases.

\section{Results}

Recall the remark in the original source (9) - GTP work at large excess air coefficients of the order $\alpha=3 \div 5$ for schemes without regeneration and $\alpha=5 \div 8$ for schemes with regeneration. That is, in the worst case scenario, in a scheme with regeneration, compared with a simple scheme, the coefficient of excess air $\alpha$ is increased by 2.67 times. So, according to formula (13), if the minimum excess air coefficient $\alpha=$ 3 is provided in the regeneration scheme, then the specific area of the recuperator $\mathrm{f} / \mathrm{N}$ can be reduced by 2.67 times.

To reduce the value of the excess air coefficient $\alpha$ in the scheme with regeneration to the values in a simple scheme, the author of the article suggests on the basis of the actually developed scheme (Sevtsov's scheme) - Fig. 4.

Compared with the Sukhachev's scheme (fig.3) in the Sevtsov's scheme (fig. 4) there is no secondary air supply pipeline to the inter-tube space of the combustion chamber. The pipeline for the supply of primary air heated in the heat exchanger inside the heat pipe to the combustion is preserved. The removal of the secondary air heating process in the recuperator was caused by the functional duty of the secondary air to serve as a cooling agent, as previously noted in the primary source [7].

The absence of additional heating of secondary air in the recuperator according to the Sevtsov's scheme (fig. 4) according to formula (2) leads to the possibility of reducing the excess air coefficient $\alpha$ in the new scheme to values characteristic of a simple scheme. 


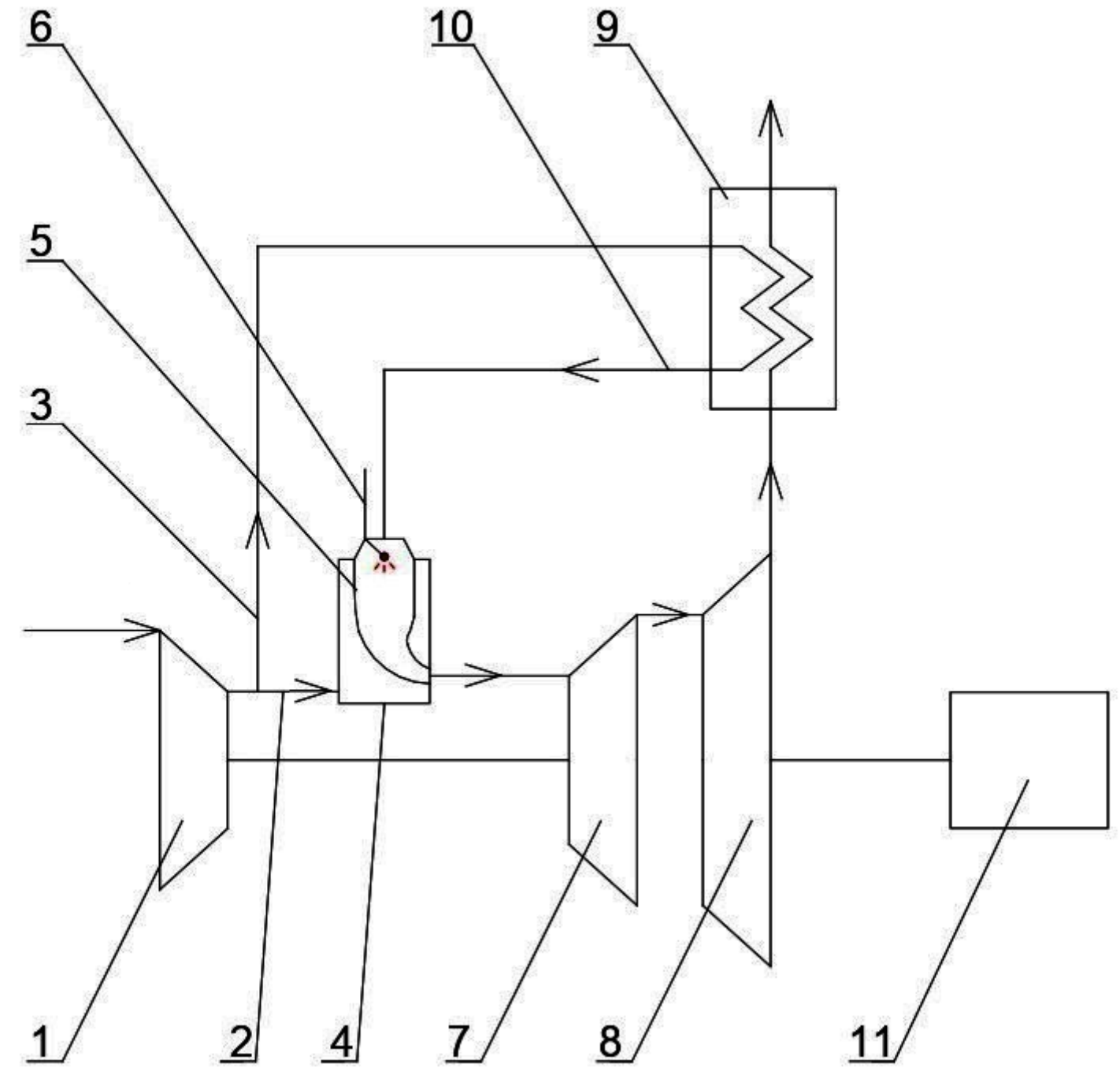

Fig. 4. Sevtsov's scheme:

1. compressor;

2. secondary air supply from the compressor to the combustion chamber housing;

3. supply of primary air from the compressor to the recuperator;

4. combustion chamber housing;

5. combustion chamber heat pipe;

6. fuel supply to the combustion chamber;

7. compressor drive turbine;

8. free power turbine;

9. recuperator;

10. supply of primary air from the recuperator into the combustion chamber heat pipe;

11. power consumer.

\section{Discussion}

But the reduction in the specific area of the recuperator $\mathrm{f} / \mathrm{N}$, calculated by the formula (13), for the new scheme (fig.4) it will not be quite correct. 
The use of formula (13) assumes that the air flow rate $G_{\text {в }}$ coincides with the flow rate of combustion products $\mathrm{G}_{\text {пс }}$.

In the case of a new scheme, these costs do not match.

Let us use the following arguments of Professor V.V. Uvarov [13].

The specific surface of a countercurrent heat exchanger with a heat exchange surface $F$ according to the formula of Prof. V.V. Uvarov -

$$
f_{\mathrm{p}}=\frac{F}{G_{\mathrm{B}}}=\frac{c_{p_{\mathrm{B}}}}{k_{\mathrm{p}}(\varphi-1)} \ln \frac{1-\sigma}{1-\varphi \sigma}
$$

where $-\mathrm{k}_{\mathrm{p}}$ average heat transfer coefficient in the heat exchanger;

$$
\varphi=c_{p \mathrm{~B}} G_{\mathrm{B}} / c_{p n c} G_{n c}(15)
$$

combustion products.

It follows from formula (14) that with an increase in the degree of regeneration $\sigma$, the specific surface area of $\mathrm{fp}$ increases. The surface $\mathrm{fp}$ tends to infinity at $\sigma=1$ if $\varphi \leq 1$, and at $\sigma=1 / \varphi$ if $\varphi>1$ (Fig. 5).

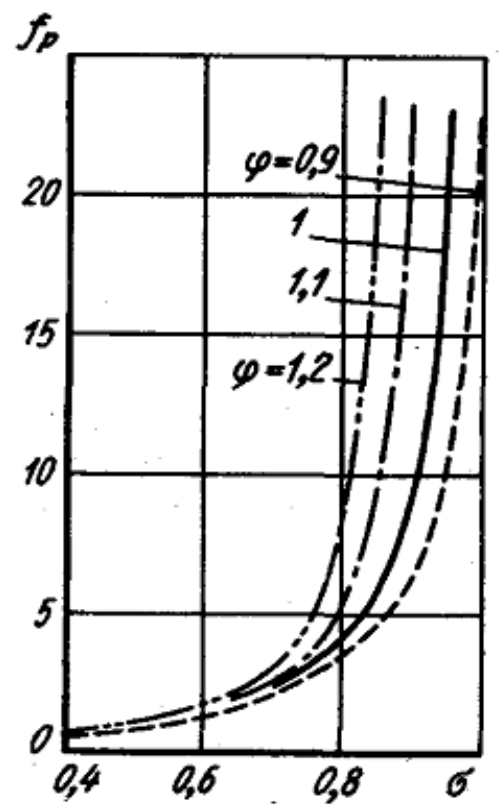

Fig. 5. The effect of the degree of regeneration on the specific surface of the regenerative gas turbine unit recuperator.

When $\varphi=1$, formula (14) gives an uncertainty of type $\infty / \infty$.

After revealing the uncertainty, we obtain the previously considered formula (8)

$$
\frac{f}{G}=\frac{c p_{\mathrm{B}}}{K} \cdot \frac{\sigma}{1-\sigma}
$$

where $-\mathrm{K}=\mathrm{k}_{\mathrm{p}}$.

As a result, we have that even at $\varphi \leq 1$, obtaining the degree of regeneration $\sigma=1$, as determined by Prof. V.V. Uvarov, is not feasible, since it requires an infinitely large recuperator.

In the new scheme, $\phi<1$. Therefore, for the new scheme, the dependence of the specific surface of the recuperator on the degree of regeneration with a ratio of water equivalents of air and gas $\varphi \leq 1$, shown 
in Fig. 6 [14], is relevant.

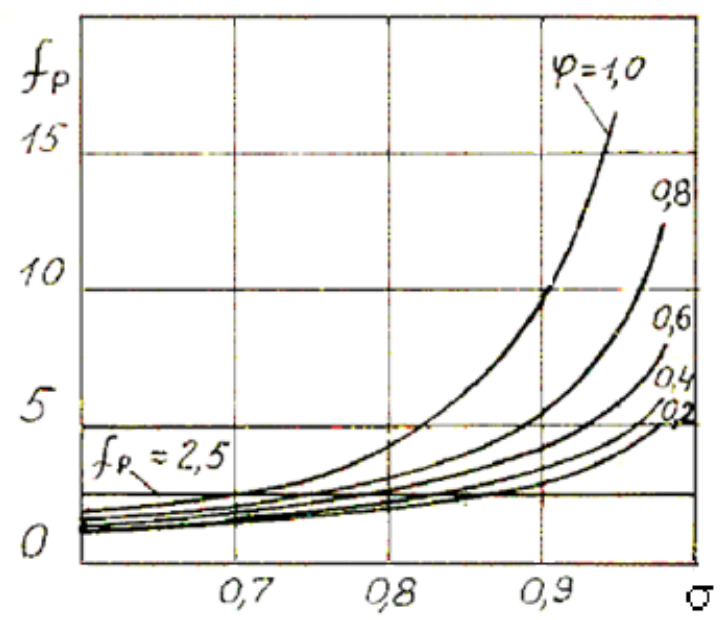

Fig. 6. The dependence of the specific surface of the regenerator on the degree of regeneration with a ratio of water equivalents of air and gas $\varphi \leq 1$.

Let's write a formula for the total air flow G taking into account the primary air flow GI, the secondary air flow GII and the excess air coefficient $\alpha-$

$\mathrm{G}=\mathrm{GI}+\mathrm{GII}=\mathrm{GI}+(\alpha-1) \cdot \mathrm{GI}=\alpha \cdot \mathrm{GI}(16)$

From the original source [9], we choose $\alpha=3 \div 5$ for the Sevtsov's scheme (as for a simple scheme). Then the total gas consumption $\mathrm{G}$ will be equal to $3 \div 5$ of the primary air GI -

$\mathrm{G}=(3 \div 5) \cdot$ GI $(17)$.

The primary air consumption is thus equal to -

$\mathrm{GI}=\mathrm{G} /(3 \div 5)(18)$.

According to Sevtsov's scheme (Fig. 4) the air flow rate Gв in V.V. Uvarov's formula (14) is equal to the primary air flow rate GI in formula (18).

That is, in the Sevtsov's scheme, the specific surface of the recuperator $\mathrm{f} p$ is greater than the specific surface of the recuperator $\mathrm{f} p$ GTP of the classical installation according to a simple - non-regenerativescheme by $3 \div 5$ times.

This is the first reserve for increasing the degree of regeneration of $\sigma$ in the new installation.

If the values of the heat capacities of the Срв air and the combustion products of the Cпс are equal, then formula (15) the ratio of the water equivalents of air and combustion products, taking into account formula (16), can be written as follows -

$$
\varphi=\mathrm{GI} /(\alpha-1) \mathrm{GI}=1 / \alpha-1 \text { (19) }
$$

Taking into account the original source [9], we have values of $\phi$ within $\varphi=0.25 \div 0.5$.

According to Fig. 6, in the zone of high values of the degree of regeneration $\sigma>0,9$, the specific surface of the recuperator $f p$ of the new scheme will on average be less than the specific surface of the recuperator $f p$ the "classical" regenerative scheme is 3 times (15 vs. 5).

This is the second reserve for increasing the degree of regeneration of $\sigma$ in the new installation.

\section{Conclusions}

As a result, taking into account the first and second reserves, in the new regenerative GTP scheme, the specific surface area of the recuperator can be increased by an average of 9-15 times compared to the old scheme. Moreover, this increase in the specific surface of the recuperator in the new scheme is achieved without an increase in the hydraulic resistance of the recuperator.

It can be concluded that there is an option to eliminate the previously described technological deadlock in the growth of efficiency coefficient of regenerative GTP.

The article discusses the industrial drive GTP. 
But in principle, if we strive to achieve the minimum size of the recuperator with a slight decrease in the maximum efficiency coefficient, then we can use a new thermal scheme and two reserves found to increase the specific surface of the recuperator for the design of microturbines and transport (for example, aviation - helicopter, turboprop, dual-circuit turbojet) gas turbine engines.

The work was carried out on the personal initiative of the author in his personal time without involving other persons and organizations.

\section{References}

1.Ardatov K. V., Nesterenko V. G., Ravikovich Y. A. . «Classification of high-performance recuperators GTE»/«Electronic journal «Trudy MAI»», 2013, №7.

2. p. 769. Mechanical engineering. Encyclopedia. Ed. council: K.V. Frolov (pred.) and others- M: Mechanical Engineering. Turbine installations. T. IV-19/ V.A. Rassokhin, L.A. Khomenok, V.B. Mikhailov, etc.; edited by Yu.S. Vasidbev. 2015.-1030 p., ill.

3. p. 57. Construction and design of ground-based gas turbine engines: lecture notes/ M.A. Nihamkin. Perm: Publishing house of Perm. nats. research. polytech. un-ta, 2011.-93 p.

4. pp. 417-418. Theory and design of gas turbine and combined installations: textbook for universities/ [A.N. Arbekov et al.]; under the general Ed. of A.Y. Varaksin.-4th ed., ispr.-Moscow: Publishing House of Bauman Moscow State Technical University, 2017.-678, [2] p.: ill.

5. pp. 216, 235, 319. Gas turbine installations: history and prospects: Monograph/ V.A. Hristich, G.B. Varlamov.-K.:NTUU "KPI", 2006.-384 p.: ill.

6. p.30. Gas turbine installations: history and prospects: Monograph / V.A. Hristich, G.B. Varlamov.K.:NTUU "KPI", 2006.-384 p.: ill.

7. p.87, L.A. Kuznetsov, Combustion chambers of stationary gas turbine installations. State Scientific and Technical Publishing House of Machine-building Literature/Moscow.1957.Leningrad.

8. p. 251, 252. Mechanical engineering. Encyclopedia/Ed. Council: K.V. Frolov (pred.) and others.-M.: Mechanical Engineering. Planes and helicopters. Vol. IV-21. Aircraft engines. Book 3/ V.A. Skibin, V.I. Solonin, Yu.M. Temis and others; edited by V.A. Skibin, Yu.M. Temis and V.A. Sosunov.-2010.-720 p.; ill.

9. Pp. 30-31 I.V. Kotlyar/Marine gas turbine installations. Publishing house "Shipbuilding". Lentngrad1967.

10. Page 14. Komarov, O.V. Thermal and gas-dynamic calculations of gas turbine installations: an educational and methodical manual/O.V. Komarov, V.L. Blinov, A.S. Shemyakinsky.-Yekaterinburg: Ural Publishing House. un-ta, 2018.-164 p.

11. Pp. 12, 14-17. Kostyuk A.G., Sherstyuk A.N. Gas turbine installations: Textbook for universities.-M.: Higher School, 1979.-254 p., ill.

12. Page 42. Uvarov V.V. Gas turbines and gas turbine installations. Studies. Manual for mechanical engineering. universities and faculties. M.. "Higher School", 1970. 320 p. with fig.

13. Pp. 84-85. Theory and design of gas turbine and combined installations: Textbook for universities/ Y.S. Eliseev, E.A. Manushkin, V.E. Mikhaltsev et al. - 2nd ed., reprint. and additional-M.: Publishing House of the Bauman Moscow State Technical University, 2000.-640 p.

14. V.A.Ivanov «EFFICIENCY OF COMPLEX CYCLES OF GAS TURBINE UNITS WITH AIR BLEED FOR THE COOLING OF INTERMEDIATE COMBUSTION CHAMGERS»/ VESTNIK OF SAMARA UNIVERSITY. AEROSPACE AND MECHANICAL ENGINEERING. №5 (47), часть 4, 2014. 